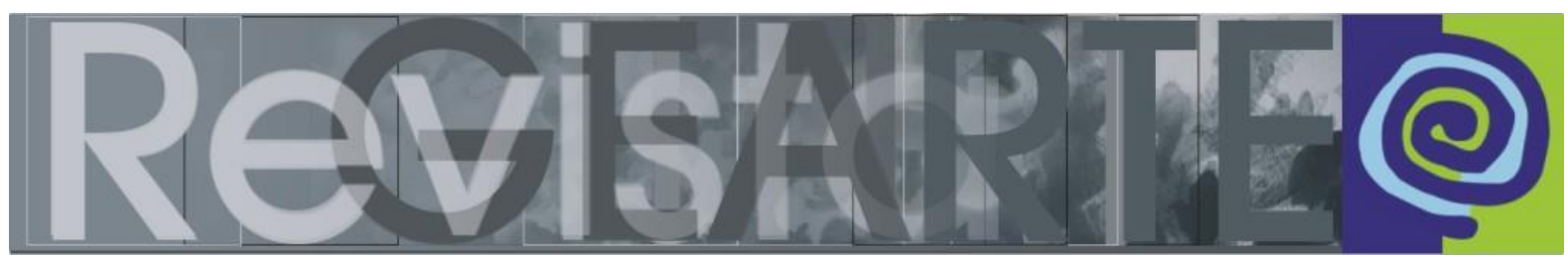

ISSN 2357-9854 | e-ISSN 2596-3198 (online)

\title{
Um congresso participativo
}

\author{
Ana Mae Barbosa \\ (Universidade de São Paulo - USP/ Universidade Anhembi \\ Morumbi — UAM, São Paulo/SP, Brasil)
}

\begin{abstract}
O que é crucial ter em mente é que a "colonialidade" e todos os conceitos que introduzimos desde então são conceitos cujo ponto de origem não está na Europa mas no "Terceiro Mundo". Isso significa que todos esses conceitos emergem da experiência de colonialidade nas Américas. Enredado com a modernidade, com certeza, mas não mais "aplicando" categorias nascidas na Europa para "entender" os legados coloniais. Pelo contrário, convertemos a Europa em um campo de análise, em vez de um provedor de "recursos culturais e epistêmicos". (MIGNOLO, 2014)
\end{abstract}

Meu principal problema para organizar o Congresso de Ensino/ Aprendizagem das Artes na América Latina: colonialismo e questões de gênero foi democratizar o tempo de fala, isto é, os participantes/ouvintes, que em geral têm apenas 15 minutos para perguntas depois das palestras, terem o mesmo tempo de fala dos conferêncistas - como explicarei mais adiante - algo diferente do costumeiro nos modelos oficiais de congressos acadêmicos.

Outro problema foi solicitar mais trabalho aos professores formadores de professores, além do que eles têm cotidianamente, pedindo que preparassem seus alunos para discutir os temas acerca de decolonização e flexibilidade de gênero nas agendas de produção e recepção das Artes, pouco discutidos no currículo das Licenciaturas em Artes.

O ensino/aprendizagem da arte na América Latina, sob diferentes designações, como Educação Artística, Educação pela Arte e/ou Arte/Educação, se desenvolveu muito nos últimos 30 anos graças aos mestrados e doutorados e à ação das ONGs que pretendiam a reconstrução social dos seres humanos humilhados e desprezados pelas instituições e outras variáveis degradantes da vida, mas academicamente nos mantivemos colonizados pelos códigos europeu e norte-americano branco. 


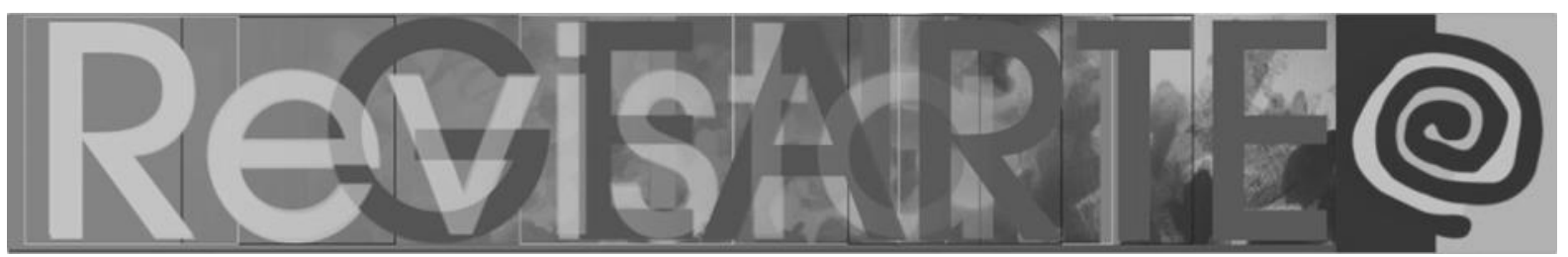

As pesquisas nas pós-graduações venceram a anemia teórica dos anos 1970, criando bases comprováveis e confiáveis para a ação no chão da escola. A educação não formal e as ONGs provaram a necessidade da Arte para desenvolver o raciocínio intelectual e crítico, a percepção e os processos criativos, que são importantes para todas as áreas de aprendizagem, quer sejam medicina ou tecnologias digitais.

No Brasil, o SESC foi uma das intuições que mais colaborou para essas conquistas e abriu suas portas para acolher o Consejo Latinoamericano de Educación por el Arte (CLEA), apoiado por várias outras instituições, no Congresso de 2019. O CLEA, por minha iniciativa, foi criado em 1984 no Congresso Mundial da InSEA, no Rio de Janeiro. O CLEA tem representantes de dez países latino-americanos, que vêm trabalhando ininterruptamente desde então, no sentido de nos reforçarmos mutualmente, respeitando nossas diferenças sem cairmos na tentação, aparentemente fácil, mas impossível, da homogeneização das práticas e teorias, como vem sendo tentado no Ensino da Arte no Brasil há 200 anos, através de processos colonizadores.

Podemos passear por diferentes influências, mas rejeitamos o colonialismo cultural através de imposição legal, como vem acontecendo até hoje.

Nos anos 1970, o sistema de ensino da Arte do Brasil foi desenhado pela Universidade de São Diego (EUA); nos anos 1990, por um espanhol que nunca viveu no Brasil, e agora voltamos a ser dominados por bancos e outras corporações que pressionam o MEC a retirar Arte do currículo da educação básica, particularmente do ensino médio. Em 2018 Arte deixou de ter obrigatoriedade no Ensino Médio. Este Congresso pretende intensificar a conscientização e as ações de combate à colonização cultural, econômica, educacional e emocional. Arte/Educação no Brasil é feminina, isto é, dominada por mulheres que têm que lutar contra duas desqualificações ao mesmo tempo: a desqualificação do trabalho da mulher e a desqualificação da Arte no sistema educacional. Por isso foram também discutidos os problemas que levam a ser necessária uma decolonização de gênero. 


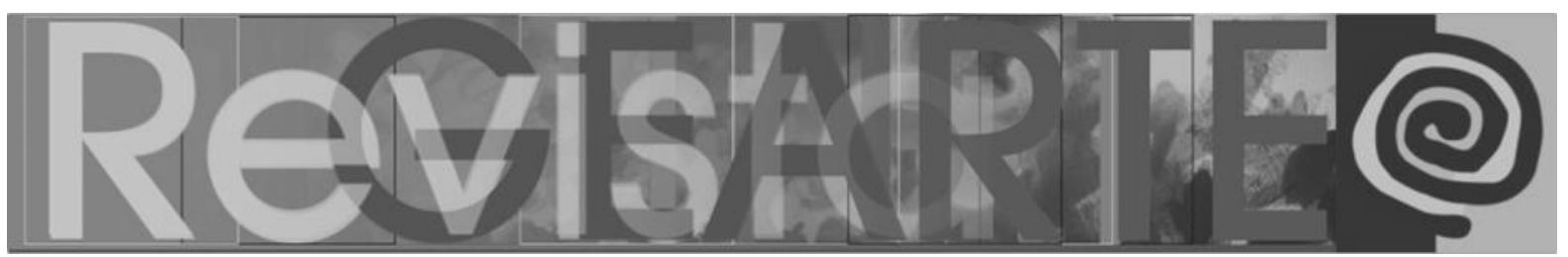

A prioridade deste Congresso foi os debates entre todos os participantes. Tivemos nove horas de debates com a sistematização de relatores e coordenadores para chegarmos a conclusões operacionalizáveis. Foi dedicado aos debates o mesmo tempo dedicado às conferências e mesas como um conjunto. Os participantes tiveram o mesmo tempo de fala que o tempo de ouvir a fala dos outros.

Precisamos aprender a valorizar nossa cultura, para evitar a destruição dos museus que estudam nossa história. Todo cidadão de um país precisa conhecer sua arte e sua história ou continuaremos a gastar mais com prisões do que com a educação, o que é um atestado de incompetência administrativa e humana.

\section{Processo articipatório de organização e referências preparatórias para os debates}

No início de 2018 convidamos 71 arte/educadores de diversos estados do Brasil para colaborarem com a preparação deste Congresso, discutindo com seus alunos os temas a serem debatidos. Duas longas - mas completas - bibliografias foram organizadas por dois estudiosos do decolonialismo: Eduardo Moura e Sidiney Peterson e uma, acerca do pós-feminismo, por Ana Mae Barbosa.

A pedido dos representantes dos estados do Brasil, foi feita redução nas bibliografias com a escolha de algumas publicações mais necessárias para iniciar os debates em cada estado. Havia ainda três vídeos que também podiam ajudar nessa discussão.

O recado para os representantes dos estados era: "escolha você um texto ou vídeo - ou ambos - para conversar sobre ele(s) com seus alunos, os professores de sua escola ou sua comunidade. Estão todos na internet. Você também pode escolher um texto ou vídeo que não esteja nesta lista, mas que considere pertinente para as discussões sobre os temas do Congresso. Estas são apenas sugestões para estimular os debates."

A participação dos representantes dos estados foi extraordinaria. O grupo de São Paulo se organizou em várias reuniões presenciais e por rede digital com 


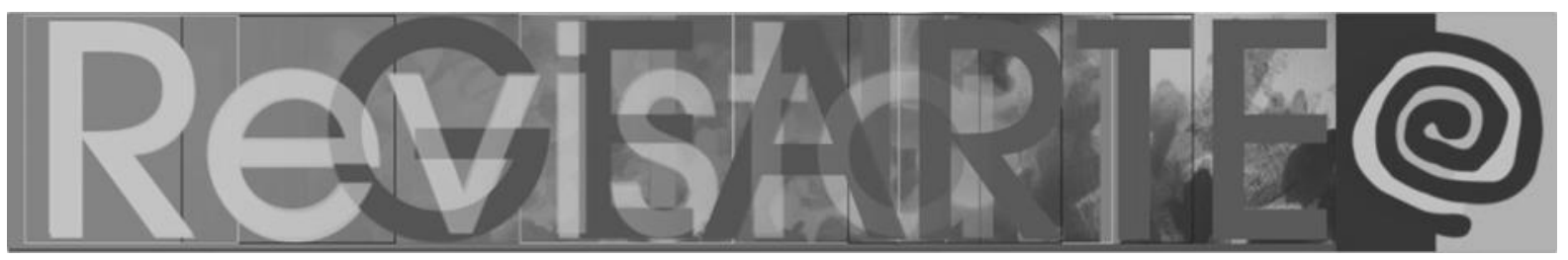

mediadores de outros estados para liderarem os debates. Tivemos mais ou menos $80 \%$ de participação das mais diferentes caracteristicas, como o professor Ângelo Roberto Barros, do Maranhão, que, além de debater os temas em dois encontros que organizou, utilizou-se, como ele próprio me informou, também "de uma livraria e espaço cultural da Associação Maranhense de Escritores Independentes - o único espaço cultural, no país, dentro de um shopping com programações artísticas, culturais e acadêmicas sobre arte e cultura diversificadas, diárias, gratuitas e com certificações, para a comunidade em geral." O grupo de representantes do Pará - Ana del Tabor, Marisa Mokarzel e Rosangela Britto - organizou, de outubro de 2018 a março de 2019, um ciclo de debates mensal com intelectuais de Belém sobre os temas do Congresso, fazendo inclusive avaliação dos resultados com o público. No quesito sobre a importância dos temas discutidos, $100 \%$ dos particpantes - na maioria alunos e professores - respondeu considerar o que foi abordado de grande relevância para seu trabalho. Vale a pena lermos o seu relatório:

\section{Experiências educativas em artes visuais na Amazônia paraense}

Para Walter Mignolo (2017) a modernidade foi constituída a partir do colonialismo, condição que permitiu se estruturar, possibilitando que a Europa e posteriormente os Estados Unidos exercessem a sua dominação, consolidando uma gestão de controle e autoridade da economia, das pessoas e do conhecimento. Dentro dessa lógica, a História da Arte foi concebida como uma história da arte eurocêntrica, silenciando as outras histórias, as manifestações artísticas de outros povos, o que vai afetar o ensino das artes em diferentes continentes. Situado em um território muitas vezes esquecido política, social e culturalmente, o Grupo de Pesquisa Arte, Memórias e Acervos na Amazônia - vinculado ao CNPq e à UFPA/PPGArtes/FAV - se propõe a discutir a temática 2 do Congresso.

Com base nesses questionamentos houve a intenção de ampliar o debate $e$ socializar as discussões através de ciclos de mesas-redondas propostos para acontecer de outubro de 2018 a fevereiro de 2019 em Belém. As quatro mesas foram pensadas como uma forma de aprofundar as problemáticas levantadas pelos 


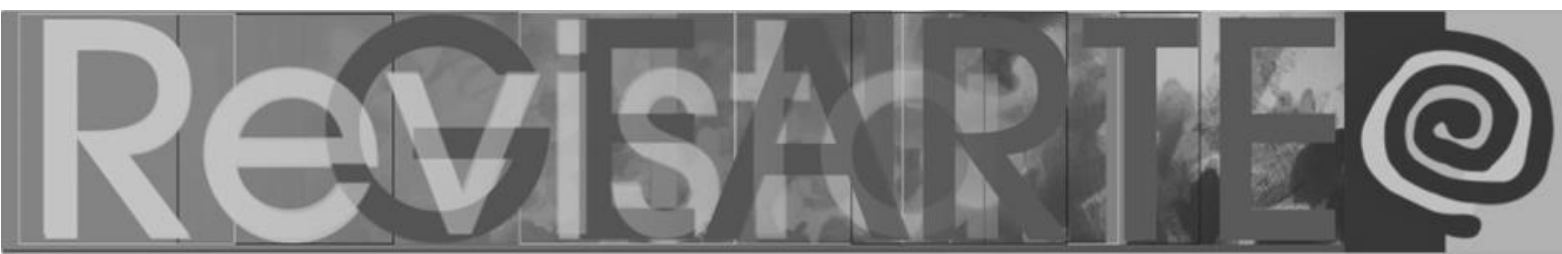

organizadores do Congresso, e assim teve-se como base as seguintes questões: Descolonialismo/decolonialismo e as questões do ensino/aprendizagem em Arte; História da Arte e o ensino/aprendizagem das Artes Visuais: uma questão de Colonialismo?; Polivalência ou Interdisciplinaridade no ensino/aprendizagem das Artes Visuais?; Abordagens étnico-raciais e gênero: da invisibilidade à visibilidade no campo da Arte.

Todas as mesas foram compostas por docentes do ensino superior e da educação básica, que aceitaram o convite para juntos pensarmos táticas e estratégias de enfrentamento dos desafios que surgem diante do cenário educacional/cultural de incertezas. Como encerramento, no mês de março de 2019, foi proposta uma conferência a partir da memória e das questões de gênero tratadas; um seminário composto por uma plenária de convidados representantes da educação básica, das instituições de ensino superior e dos Cursos de Artes do PARFOR (Plano Nacional de Formação de Professores da Educação Básica); e uma mesa que apresentou a síntese do ciclo de debates. (Prof ${ }^{a}$ Ana Del Tabor, Prof ${ }^{a}$. Rosangela Britto, Prof ${ }^{a}$ Marisa Mokarzel).

A outra forma de participação foi pedir aos inscritos no Congresso para, em lugar de Comunicações, enviarem uma página escrita sobre um dos temas a ser discutido que constasse do programa, divulgado com muita antecedência. No entanto, essa proposta de participação não deu grande resultado do ponto de vista da quantidade, mas a qualidade do que nos chegou foi muito boa.

Pretendo escrever um artigo comentando essas colaborações inestimáveis. Basta dizer que a preocupação com análise histórica dominou os textos. Recebemos até um texto lembrando a intenção da Bienal de São Paulo em discutir a latinoamericanidade em 1978, no período em que se estudava a Teoria da Dependência, destituída por um de seus criadores e agora referência meramente histórica das teorias decolonizadoras.

Para considerar este congresso como participativo basta dizer que foi construído durante um ano e meio, com a participação direta e ativa de 115 pessoas, 


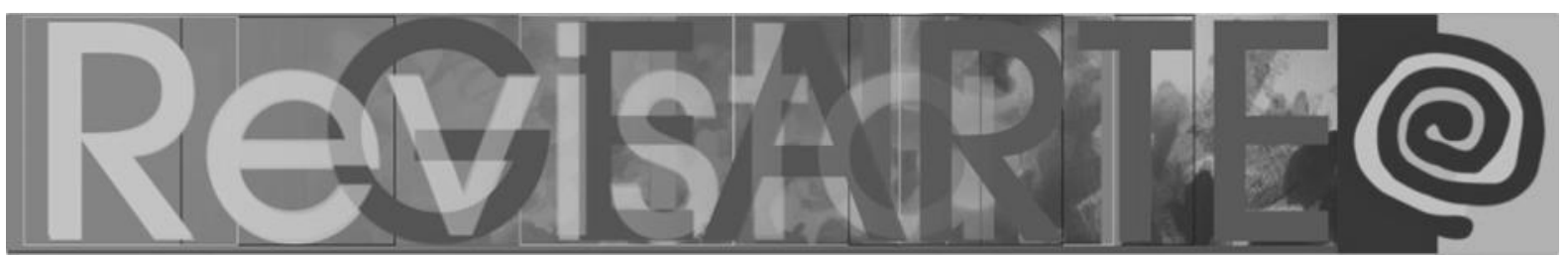

entre comissão organizadora (6), produtores (3), representantes de instituições apoiadoras (10), divulgação voluntária, mas programada (7), membros do Clea (18), representantes do congresso nos estados (71). Além dessa equipe de organizadores, tivemos 21 pensadores, como conferencistas e palestrantes, diretores de divisões do SESC e toda a equipe do SESC Vila Mariana presentes nas reuniões.

O SESC nos surpreendeu com performances todos os dias depois dos trabalhos e na despedida com um festivo lançamento do livro Mulheres não devem ficar em silêncio: arte, design, educação, organizado por Ana Mae Barbosa e Vitória Amaral (Cortez, 2019 - ISBN: 9788524927225).

Agradeço muitíssimo à equipe da Revista Gearte e sua Editora, Analice Dutra Pillar, a edição deste número.

\section{Notas}

ABREU, Simone Rocha de. Os discursos sobre a identidade da Arte latino-americana na Fundação Bienal: reflexões a partir Simpósio da I Bienal Latino-americana de 1978.

O regulamento da I Bienal Latino-americana incluiu a convocatória de "estudiosos de todas as partes do mundo, em diferentes disciplinas, para participarem do Simpósio" que ocorreu nos três primeiros dias da mostra. Também houve a definição dos temas a serem discutidos de forma bastante clara, temas bastante radicais para o período: "1 - Mitos e magia na arte latino-americana. 2 - Problemas gerais da arte latino-americana. 3 - Propostas para a II Bienal latino-americana de 1980". Essas conferências foram datilografadas e compiladas pela Fundação Bienal, apresentadas em dois volumes presentes no acervo do Arquivo Histórico Wanda Svevo da Fundação Bienal de São Paulo. É possível agrupar as conferências mediante a tônica conceitual e filosófica discursiva:

Sob a tônica da busca por um "Conceito de América Latina” podemos agrupar Darcy Ribeiro, Oscar Olea e Romanita Martins. Eles discutiram com maior ou menor engajamento o conceito de América Latina e a decorrência ou pertinência de nosso continente ser visto como uma unidade e ao mesmo tempo ser visto guardando a sua diferença em relação aos demais blocos geopolíticos.

Sob o foco temático da Bienal e do Simpósio "Mitos e magia na arte" apresentarem conferências Ernesto Sábato, Adalice Araujo, Guillermo Whitelow, Carlos Espartaco, Jorge Alberto Manrique, Marianne Tolentino, Silvia Ambrosini, Oreste Bruneto e Carmen Lariño, Donald Goodall, porque cada um a seu modo abordou as questões conceituais e referenciais sobre mitos, ritos e magia na arte.

Em um recorte dentro das especificidades da América Latina, reunimos sob a tônica das "Africanidades" Eduardo de Oliveira e Oliveira, Clyde Morgan, Raul Lody e Fernando Mourão. Esses conferencistas revelam múltiplos aspectos da nossa herança do imenso contingente de africanos trazidos durante o processo de escravidão para os diversos países latino-americanos.

A "Indianidade" não foi comtemplada com a mesma pluralidade de enfoques que as africanidades, porque somente um dos conferencistas optou por esse enfoque: Maria Heloísa Fénelon Costa.

O enfoque intitulado "Exercício da crítica - existe uma crítica latino-americana?" Reuniu Jacob Klintowitz, Carlos Silva, Galaor Carbonell e Marta Traba. Recorte do exercício da crítica com foco 


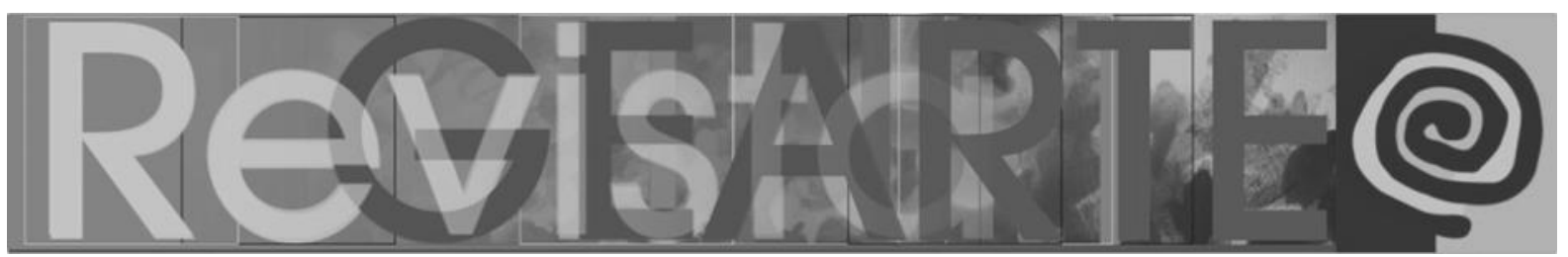

nas discussões dos "conceitos de arte e cultura" reuniu os conferencistas Mário Pedrosa, Jorge Glusberg, Néstor Garcia Canclini, Rita Eder, Bengt Oldenburg, Juan Acha, Jorge Romero Brest, Israel Pedrosa.

Outro recorte que permanece até hoje em discussão na crítica contemporânea é a divisão entre arte "culta" e popular, que na época do Simpósio (1978) era extremamente polarizada, o que colocava em confronto os críticos. Neste Simpósio, porém, houve uma concordância da importância deste "gênero" na revelação das identidades e das generosas trocas entre arte popular e a dita arte culta. A valorização da arte dita popular teve como conferencistas Eli Bartra, Lélia Coelho Frota, Alba Maria Zaluar e Mirko Lauer, que trouxeram exemplos de arte e de cultura popular que destacaram aspectos fundamentais destas atividades artísticas como resistência e de revelação de uma herança cultural.

\section{Bibliografia básica enviada aos representantes do congresso nos estados}

BIDASECA, Karina. Voces y luchas contemporáneas del feminismo negro. Corpolíticas de la violencia sexual racializada. Texto publicado em: Afrodescendencia. Aproximaciones contemporáneas de América Latina y el Caribe. Colección de ensayos del Centro de Información de las Naciones Unidas para México, Cuba y Rca. Dominicana, en el marco del Año Internacional de los Afrodescendientes, ONU, México, 2012. Disponible en: <http://www.cinu.mx/AFRODESCENDENCIA.pdf>

CAMNITZER, Luis. Texto preparado por Luis Camnitzer para a IV Semana de la Educación Artística Chile, maio, 2016. Disponível em: <http://semanaeducacionartistica.cultura.gob.cl/wp-content/u ploads/2017/03/texto-luis-camnitzer.pdf>

CATELLI, Laura. Hacia una crítica (des)colonial. Los estudios coloniales y el pensamiento descolonial. V Congreso Internacional de Letras, 2012. ISBN 978-987-3617-54-6 Disponível em: <http://2012.cil.filo .uba.ar/sites/2012.cil.filo.uba.ar/files/0095\%20CATELLI,\%20LAURA.pdf>

GÓMEZ MORENO, Pedro Pablo. La paradoja del fin del colonialismo y la permanencia de la colonialidad, Calle 14: Revista de Investigación en el Campo del Arte, v. 4, n. 4, p. 26-39, 2010. ISSNe 2145-0706. Disponível em: <https://dialnet.unirioja.es/servlet/articulo?codigo=3231097>

GÓMEZ MORENO, Pedro Pablo; MIGNOLO, Walter. Estéticas decoloniales. Bogotá: Universidad Distrital Francisco José de Caldas, 2012. Disponível em: <http://esferapublica.org/nfblog/esteticasdecoloniales-2/>

GUINTA, Andrea; FAJARDO-HILL, Cecilia. Radical Women. Entrevista. Disponível em: <http://artishockrevista.com/2017/10/05/andrea-giunta-cecilia-fajardo-hill-radical-women/>

KILOMBA, Grada. Descolonizando o conhecimento. Disponível em: <http://www.goethe.de/mmo/priv/ 15259710-STANDARD.pdf>

LOURO, Guacira L. Gênero e sexualidade: pedagogias contemporâneas. Pro-Posições, v. 19, n. 2, p. 17-23, maio/ago. 2008. Disponível em: <http://www.scielo.br/pdf/pp/v19n2/a03v19n2>

MIGNOLO, Walter. Entrevista. Em: GALLAS, Luciano. Decolonialidade como o caminho para a cooperação. Trad. André Langer. Revista do Instituto Humanitas Unisinos IHU Online, Edição 431, 2013. Disponível em: <http://www.ihuonline.unisinos.br/index.php?option=com_content\&view $=$ article $\&$ id $=5253 \&$ secao $=431 \% 20>$

MIGNOLO, Walter. Decolonial aesthetics/aesthesis has become a connector across the continents. Contemporary And, ago, 2014. Entrevista concedida a Aïcha Diallo. Disponível em: $<$ https://www.contemporaryand.com/magazines/decolonial-aestheticsaesthesis-has-become-aconnector-across-the-continent/>

MOURA, Eduardo J S. A América Latina existe! Notas para pensar a decolonialidade e a desobediência docente em artes visuais. In: Simpósio Internacional Pensar e Repensar a América Latina, 2, 2016, Anais... ISBN: 978-85-7205-159-0. Disponível em: <https://sites.usp.br/prolam/wp-content/uploads/ 


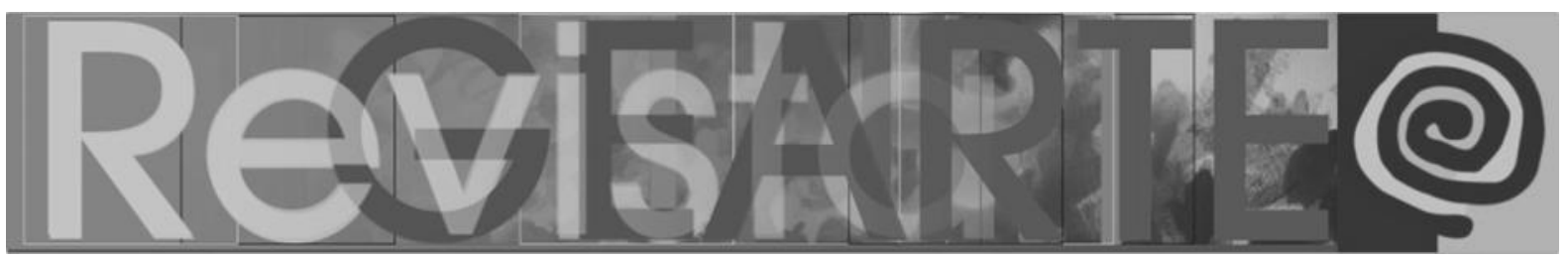

sites/35/2016/12/MOURA_SP12-Anais-do-II-Segundo-Simpósio-Internacional-Pensar-e-Repensar-aAmérica-Latina>

QUIJANO, Aníbal. Colonialidad del poder, eurocentrismo y América Latina. Disponível em: $<$ http://www.decolonialtranslation.com/espanol/quijano-colonialidad-del-poder.pdf>

RIVAS, María del Pilar Aumente. La imagen de las mujeres a través de su propia mirada. Revista Creatividad y Sociedad C/ Salud, Madrid, n. 15, nov. 2010. Disponível em: <http://www.creatividadysociedad.com/articulos/15/creatividadysociedad_la\%20imagen\%20e\%20las $\% 20$ mujeres.pdf>

WALSH, Catherine. Interculturalidad, plurinacionalidad y decolonialidad: las insurgencias políticoepistémicas de refundar el Estado. Tabula Rasa, Bogotá, Colombia, n. 9, p. 131-152, jul.-dic. 2008. ISSN 1794-2489. Disponível em: <www.scielo.org.co/pdf/tara/n9/n9a09>

WALSH, Catherine. Interculturalidad crítica y educación intercultural. Disponível em: <www.uchile.cl (no campo de busca, colar o nome da autora e título do livro).

\section{Vídeos}

ADICHIE, Chimamanda Ngozi. O perigo da história única. TED Talks. Disponível em: $<\mathrm{https}: / /$ www.ted.com/talks/chimamanda_adichie_the_danger_of_a_single_story?language=pt >

DUSSEL, Enrique. El giro descolonizador. Disponível em: <https://www.youtube.com/ watch? $\mathrm{v}=\mathrm{m} \mid 9 \mathrm{~F} 73 \mathrm{wIMQE}>$

MIGNOLO, Walter. Estéticas decoloniales. Disponível em: <https://www.youtube. $\mathrm{com} /$ watch? $\mathrm{v}=$ mqtqtRj5vDA>

\section{Ana Mae Barbosa}

Possui graduação em Direito pela Universidade Federal de Pernambuco (1960), mestrado em Art Education pela Southern Connecticut State College (1974) e doutorado em Humanistic Education pela Boston University (1978). Atualmente é professora titular aposentada da Universidade de São Paulo e professora da Universidade Anhembi Morumbi. Foi presidente da International Society for Education through Art (InSEA), da Associação Nacional de Pesquisadores em Artes Plásticas (ANPAP) e diretora do Museu de Arte Contemporânea da USP (MAC/USP). Tem livros e artigos publicados em diversos países. Tem experiência na área de Artes, com ênfase em Arte/Educação, atuando principalmente nos seguintes temas: Ensino da Arte e contextos metodológicos, História do Ensino da Arte e do Desenho, Ensino do Design, Administração de Arte, Multiculturalidade, Estudos de Museus de Arte e Estudos Visuais.

E-mail: anamaebarbosa@gmail.com

ORCID: https://orcid.org/0000-0002-4966-2043

Currículo: http://lattes.cnpq.br/1650414096296319

Recebido em 3 de março de 2019 Aceito em 21 de maio de 2019 